\title{
Use of genetics for personalized management of heritable thoracic aortic disease: How do we get there?
}

\author{
Dianna M. Milewicz, MD, PhD, and Ellen S. Regalado, MS, CGC
}

The major diseases affecting the thoracic aorta are aortic aneurysms and acute aortic dissections. Medical treatments can slow the enlargement of aneurysms, but the mainstay of treatment to prevent premature death resulting from dissection is surgical repair of the thoracic aortic aneurysm, which is typically recommended when the aortic diameter reaches 5.0 to $5.5 \mathrm{~cm}$. Studies of patients with acute aortic dissections, however, indicate that as many as $60 \%$ of dissections occur at aortic diameters smaller than $5.5 \mathrm{~cm}$. Clinical predictors are therefore needed to distinguish those at risk for dissection at an aortic diameter smaller than $5.0 \mathrm{~cm}$ and to determine the aortic diameter that justifies the risk of surgical repair to prevent an acute aortic dissection. Data from genetic studies during the past decade have established that mutations in specific genes can distinguish patients at risk for the disease and predict the risk of early dissection at diameters smaller than $5.0 \mathrm{~cm}$. This information has the potential to optimize the timing of aortic surgery to prevent acute dissections. ( $\mathrm{J}$ Thorac Cardiovasc Surg 2015;149:S3-5)

The major diseases affecting the thoracic aorta are thoracic aortic aneurysms and thoracic acute aortic dissections (together termed TAADs). The natural history of ascending thoracic aortic aneurysm (TAA) is asymptomatic enlargement with time until the occurrence of an ascending aortic dissection (Stanford type A). Less deadly dissections originate in the descending thoracic aorta distal to the left subclavian artery (Stanford type B). Although medical treatments can slow aneurysm enlargement, the mainstay of treatment to prevent premature death resulting from a dissection is surgical repair of the TAA. This intervention is typically recommended when the aortic diameter reaches 5.0 to $5.5 \mathrm{~cm}^{1}$; however, studies of patients with acute type A aortic dissections indicate that up to $60 \%$ of such dissections occur at aortic diameters smaller than $5.5 \mathrm{~cm}^{2}$ Clinical predictors are therefore needed to distinguish those at risk for dissection at an aortic diameter smaller than 5.0 $\mathrm{cm}$ and to determine the aortic diameter that justifies the risk of surgical repair to prevent an acute dissection. Genetic studies during the past decade have established that mutations in specific genes can distinguish patients at risk for the disease and predict the risk of early dissection at

\footnotetext{
From the John Ritter Research Program in Aortic and Vascular Diseases, Department of Internal Medicine, University of Texas Health Science Center at Houston, Houston, Tex.

Work in the laboratory of D.M.M. is funded by the National Institutes of Health (grants RO1 HL62594 and P50HL083794-01), the John Ritter Research Program, the National Marfan Foundation, the Ehlers Danlos Syndrome Network, the Richard T. Pasini Funds, and the Vivian L. Smith Foundation.

Disclosures: Authors have nothing to disclose with regard to commercial support.

Read at The American Association for Thoracic Surgery Aortic Symposium, New York, New York, April 24-25, 2014.

Received for publication May 30, 2014; accepted for publication July 23, 2014; available ahead of print Sept 11, 2014

Address for reprints: Dianna M. Milewicz, MD, PhD, Department of Internal Medicine, University of Texas Health Science Center at Houston, 6431 Fannin, MSB 6.100, Houston, TX 77030 (E-mail: Dianna.M.Milewicz@uth.tmc.edu). 0022-5223/ $\$ 36.00$

Copyright (c) 2015 by The American Association for Thoracic Surgery http://dx.doi.org/10.1016/j.jtcvs.2014.07.070
}

diameters smaller than $5.0 \mathrm{~cm}$. This information has the potential to optimize the timing of aortic surgery to prevent acute type A dissections.

It is established that patients with Marfan syndrome (MFS), an autosomal dominant syndrome with skeletal and ocular features, are highly predisposed toward TAAD development and typically have aortic root aneurysms. ${ }^{3}$ MFS results from mutations in $F B N 1$, which encodes fibrillin-1, a component of elastin-associated microfibrils. Loeys-Dietz syndrome (LDS) is a syndrome related to MFS that also predisposes patients to TAAD development. Patients with LDS display arterial tortuosity, craniofacial abnormalities, and skeletal features associated with MFS, along with aneurysms and dissections of the aorta and other arteries and thin, translucent skin reminiscent of patients with vascular Ehlers-Danlos syndrome. ${ }^{4}$ LDS results from mutations in either the transforming growth factor- $\beta$ receptor type I or II genes (TGFBR1 and TGFBR2). More recently, heterozygous mutations in SMAD3 and TGFB2 have been identified in families that share some clinical features with MFS and LDS. . $^{5-7}$

Emerging clinical data on the phenotypes associated with specific genes provide evidence that the underlying mutation could inform patient management, including the timing of surgical repair of TAAs and the risk of additional vascular disease. For example, patients with MFS who have FBN1 mutations have a low risk of acute aortic dissection at aortic diameters smaller than $5.5 \mathrm{~cm}$ and a low risk for aneurysms of other arteries. ${ }^{8}$ Interestingly, common genetic variants in the FBN1 gene (single-nucleotide polymorphisms) increase the risk for TAAD in the general population, ${ }^{9}$ and ongoing studies are investigating whether these could help to determine which patients could be managed in a manner similar to patients with MFS. ${ }^{10}$ In contrast, data suggest that aortic dissections occur in patients with TGFBRI and TGFBR2 mutations at aortic diameters smaller than $5.0 \mathrm{~cm}$ and that these patients also 


\section{Abbreviations and Acronyms \\ FTAAD $=$ familial thoracic acute aortic dissection \\ LDS = Loeys-Dietz syndrome \\ MFS = Marfan syndrome \\ SMC $=$ smooth muscle cell \\ TAA = ascending thoracic aortic aneurysm \\ $\mathrm{TAAD}=$ thoracic aortic aneurysm and thoracic acute aortic dissection}

have aneurysms and dissections of other arteries. ${ }^{4,11}$ These findings led to the recommendation in the American College of Cardiology Foundation and American Heart Association treatment guidelines for thoracic aortic disease that the underlying genetic mutation should dictate the timing of aortic repair. The current recommendation for patients with LDS is repair of the aorta at $4.2 \mathrm{~cm}^{1}$; however, many European countries treat LDS and MFS similarly and perform repair when the aorta reaches $5.0 \mathrm{~cm}$, surprisingly without observing premature dissections in either patients MFS or those with LDS. ${ }^{12}$ In addition, studies suggest that the risk of aortic dissection with minimal enlargement may be less for individuals with TGFBR1 mutations than for those with TGFBR2 mutation. ${ }^{11}$

As many as $20 \%$ of patients with nonsyndromic TAAD have first-degree relatives with a history of TAAD, indicating a significant genetic contribution to the disease. Analysis of these familial TAAD (FTAAD) pedigrees has shown that TAAD is primarily inherited as a single-gene, autosomal dominant condition with reduced penetrance. ${ }^{13,14}$ These families demonstrate variable expression of TAAD, with variation in the age of disease onset, risk of ascending aortic dissections at diameters smaller than $5.0 \mathrm{~cm}$, prevalence of type B dissections, and involvement of the aortic root, the ascending aorta, or both (fusiform aneurysms involving the root and ascending aorta). In addition, families with FTAAD show variable cosegregation of other cardiovascular complications with TAAD. These may include bicuspid aortic valve, patent ductus arteriosus, abdominal aortic aneurysms, and other vascular diseases (eg, intracranial aneurysms, other arterial aneurysms, and occlusive arterial disease). ${ }^{13,15-18}$ Nine genes that predispose toward autosomal dominant FTAAD have been identified to date. ${ }^{6,711,15,17,19-21}$ FBN1, TGFBR1, TGFBR2, SMAD3, and TGFB2 mutations have been identified in approximately $6 \%$ to $8 \%$ of families with FTAAD with no features of MFS or LDS, suggesting a similar pathogenesis for aneurysm formation between syndromic disease and FTAAD. ${ }^{6,7,11,20,22}$ Mutations in ACTA2, MYH11, MYLK, and PRKG1 have also been identified in families with FTAAD without MFS or LDS features.
These genes are all involved in vascular smooth muscle cell (SMC) contraction and are termed SMC contractile genes. SMCs are arranged circumferentially in multiple layers in arteries. For contractile function, SMCs express smooth muscle-specific isoforms of $\alpha$-actin and myosin (encoded by ACTA2 and MYH11, respectively), which polymerize to form thin and thick filaments, respectively. MYLK and PRKGl encode kinases that control SMC contraction and relaxation, respectively. Loss-of-function mutations have been identified in $M Y L K$, and gain-offunction mutations have been found in PRKG1. ${ }^{19,21}$ Of these, ACTA2 is the most commonly altered gene in FTAAD and is responsible for disease in $14 \%$ of patients. ${ }^{17}$ The other contractile genes contribute to $4 \%$ of FTAAD. In addition to FTAAD, ACTA2 mutations predispose toward development of occlusive vascular diseases in smaller arteries, including early-onset coronary artery disease, stroke, moyamoyalike cerebrovascular disease, and primary pulmonary hypertension. ${ }^{18,23,24}$

We examined aortic disease, management, and outcome associated with the first aortic event (defined as dissection or TAA repair) in a cohort of patients with ACTA2 mutations (unpublished data). Aortic disease presentation associated with ACTA2 mutations differed from that associated with MFS. Patients with ACTA2 mutations had fusiform aneurysms involving the aortic root and ascending aorta and were more likely to present with acute dissection than were patients with MFS. For individuals undergoing surgical repair of fusiform TAAs without evidence of dissection, the maximum diameter was either in the aortic root or in the ascending aorta and ranged from 4.2 to $6.5 \mathrm{~cm}$. In contrast, the maximum diameter ranged from 3.8 to $9.5 \mathrm{~cm}$ at presentation with an acute type A dissection. Thus, although cardiovascular surgeons followed the guidelines established for patients with MFS, a third of the individuals with ACTA2 mutations had dissection at aortic diameters smaller than $5 \mathrm{~cm}$. These data suggest that surgical repair of a TAA in an individual with ACTA2 mutation should be considered when the aorta reaches a diameter of $4.5 \mathrm{~cm}$.

The question remains as to whether aortic diameter at the time of dissection can be used to guide decisions about when to repair the aorta in individuals with genetically triggered thoracic aortic disease. A recent study sought to determine whether thoracic aortic diameter or geometry was altered by acute type A aortic dissection by comparing computed tomographic images obtained within 2 years of a dissection with computed tomographic images obtained at presentation with dissection from patients who did not have MFS or a bicuspid aortic valve. ${ }^{25}$ Most of the patients in the study had a type $\mathrm{B}$ dissection, and the dissection of the ascending aorta was retrograde. The ascending aorta was found to increase significantly in diameter and volume after dissection, suggesting that ascending aortic diameters noted at presentation after dissection do not accurately reflect the size of the 
aorta just before and at the time of dissection. Importantly, however, the aortic root diameter was not seen to be significantly altered after an acute aortic dissection.

Guidelines for surgical repair of the aorta that are based on the aortic diameter at dissection thus cannot use the size of the dissected ascending aorta as a reliable gauge, but the size of the aortic root may be used as a reliable gauge because it is not distorted by dissections. Because the majority of genetically triggered aneurysms involve the aortic root, which is typically monitored to determine timing of surgical repair, the size of the aortic root specifically should be collected to assemble the most reliable data for setting surgical guidelines for aortic repair in patients with specific gene mutations.

In summary, many patients with genetically triggered thoracic aortic disease appear to have an increased risk of aortic dissection despite little to no enlargement of the aorta. The ideal way to determine the risk associated with each gene would be to obtain computed tomographic images proximately before dissection to determine the diameter of the aorta just before the dissection. Such images are rarely available, however, so data should be obtained from postdissection images and measurements made that include the aortic root and ascending aorta. Because these patients typically demonstrate aortic root enlargement, and studies have shown that aortic root diameter is not significantly distorted after dissection, postdissection aortic root measurements may be used to guide decisions about surgical intervention on the basis of aortic diameter. Ideally, better biomarkers than aortic diameter will be available to assess the risk of acute aortic dissection in the future. Until these have been developed, however, it is critical to ensure that the most accurate data are gathered to inform guidelines for surgical management of genetically triggered aortic disease.

We are grateful to Drs Bartosz Rylski and Emanuela Branchetti for helpful discussion.

\section{References}

1. Hiratzka LF, Bakris GL, Beckman JA, Bersin RM, Carr VF, Casey DE Jr, et al; American College of Cardiology Foundation/American Heart Association Task Force on Practice Guidelines; American Association for Thoracic Surgery; American College of Radiology; American Stroke Association; Society of Cardiovascular Anesthesiologists; Society for Cardiovascular Angiography and Interventions; Society of Interventional Radiology; Society of Thoracic Surgeons; Society for Vascular Medicine. 2010 ACCF/AHA/AATS/ACR/ASA/ SCA/SCAI/SIR/STS/SVM guidelines for the diagnosis and management of patients with Thoracic Aortic Disease: a report of the American College of Cardiology Foundation/American Heart Association Task Force on Practice Guidelines, American Association for Thoracic Surgery, American College of Radiology, American Stroke Association, Society of Cardiovascular Anesthesiologists, Society for Cardiovascular Angiography and Interventions, Society of Interventional Radiology, Society of Thoracic Surgeons, and Society for Vascular Medicine. Circulation. 2010;121:e266-369. Erratum in: Circulation. 2010;122:e410.

2. Pape LA, Tsai TT, Isselbacher EM, Oh JK, O'gara PT, Evangelista A, et al; International Registry of Acute Aortic Dissection (IRAD) Investigators. Aortic diameter $\geq 5.5 \mathrm{~cm}$ is not a good predictor of type A aortic dissection: observations from the International Registry of Acute Aortic Dissection (IRAD). Circulation. 2007;116:1120-7.
3. Pyeritz RE, McKusick VA. The Marfan syndrome: diagnosis and management. N Engl J Med. 1979;300:772-7.

4. Loeys BL, Schwarze U, Holm T, Callewaert BL, Thomas GH, Pannu H, et al. Aneurysm syndromes caused by mutations in the TGF-beta receptor. $N$ Engl J Med. 2006;355:788-98.

5. van de Laar IM, Oldenburg RA, Pals G, Roos-Hesselink JW, de Graaf BM, Verhagen JM, et al. Mutations in SMAD3 cause a syndromic form of aortic aneurysms and dissections with early-onset osteoarthritis. Nat Genet. 2011;43:121-6.

6. Regalado ES, Guo DC, Villamizar C, Avidan N, Gilchrist D, McGillivray B, et al. Exome sequencing identifies SMAD3 mutations as a cause of familial thoracic aortic aneurysm and dissection with intracranial and other arterial aneurysms. Circ Res. 2011;109:680-6.

7. Boileau C, Guo DC, Hanna N, Regalado ES, Detaint D, Gong L, et al. TGFB2 mutations cause familial thoracic aortic aneurysms and dissections associated with mild systemic features of Marfan syndrome. Nat Genet. 2012;44:916-21.

8. Milewicz DM, Dietz HC, Miller DC. Treatment of aortic disease in patients with Marfan syndrome. Circulation. 2005;111:e150-7.

9. Lemaire SA, McDonald ML, Guo DC, Russell L, Miller CC 3rd, Johnson RJ, et al. Genome-wide association study identifies a susceptibility locus for thoracic aortic aneurysms and aortic dissections spanning FBN1 at 15q21.1. Nat Genet. 2011;43:996-1000.

10. Iakoubova OA, Tong CH, Rowland CM, Luke MM, Garcia VE, Catanese JJ, et al Genetic Variants in FBN-1 and Risk for Thoracic Aortic Aneurysm and Dissection. PLoS One. 2014;9:e91437.

11. Tran-Fadulu V, Pannu H, Kim DH, Vick GW 3rd, Lonsford CM, Lafont AL, et al Analysis of multigenerational families with thoracic aortic aneurysms and dissections due to TGFBR1 or TGFBR2 mutations. J Med Genet. 2009;46:607-13.

12. Attias D, Stheneur C, Roy C, Collod-Béroud G, Detaint D, Faivre L, et al Comparison of clinical presentations and outcomes between patients with TGFBR2 and FBN1 mutations in Marfan syndrome and related disorders. Circulation. 2009;120:2541-9.

13. Milewicz DM, Chen H, Park ES, Petty EM, Zaghi H, Shashidhar G, et al Reduced penetrance and variable expressivity of familial thoracic aortic aneurysms/dissections. Am J Cardiol. 1998;82:474-9.

14. Albornoz G, Coady MA, Roberts M, Davies RR, Tranquilli M, Rizzo JA, et al. Familial thoracic aortic aneurysms and dissections-incidence, modes of inheritance, and phenotypic patterns. Ann Thorac Surg. 2006;82:1400-5.

15. Zhu L, Vranckx R, Khau Van Kien P, Lalande A, Boisset N, Mathieu F, et al Mutations in myosin heavy chain 11 cause a syndrome associating thoracic aortic aneurysm/aortic dissection and patent ductus arteriosus. Nat Genet. 2006;38:343-9.

16. Loscalzo ML, Goh DL, Loeys B, Kent KC, Spevak PJ, Dietz HC. Familial thoracic aortic dilation and bicommissural aortic valve: a prospective analysis of natural history and inheritance. Am J Med Genet A. 2007;143A:1960-7.

17. Guo DC, Pannu H, Tran-Fadulu V, Papke CL, Yu RK, Avidan N, et al. Mutations in smooth muscle alpha-actin (ACTA2) lead to thoracic aortic aneurysms and dissections. Nat Genet. 2007;39:1488-93. Erratum in: Nat Genet. 2008;40:255.

18. Guo DC, Papke CL, Tran-Fadulu V, Regalado ES, Avidan N, Johnson RJ, et al Mutations in smooth muscle alpha-actin (ACTA2) cause coronary artery disease, stroke, and Moyamoya disease, along with thoracic aortic disease. Am J Hum Genet. 2009;84:617-27.

19. Wang L, Guo DC, Cao J, Gong L, Kamm KE, Regalado E, et al. Mutations in myosin light chain kinase cause familial aortic dissections. Am J Hum Genet 2010;87:701-7. Erratum in: Am J Hum Genet. 2011;88:516.

20. Milewicz DM, Michael K, Fisher N, Coselli JS, Markello T, Biddinger A Fibrillin-1 (FBN1) mutations in patients with thoracic aortic aneurysms. Circulation. 1996;94:2708-11.

21. Guo DC, Regalado E, Casteel DE, Santos-Cortez RL, Gong L, Kim JJ, et al Recurrent gain-of-function mutation in PRKGI causes thoracic aortic aneurysms and acute aortic dissections. Am J Hum Genet. 2013;93:398-404.

22. Pannu H, Fadulu V, Chang J, Lafont A, Hasham SN, Sparks E, et al. Mutations in transforming growth factor-beta receptor type II cause familial thoracic aortic aneurysms and dissections. Circulation. 2005;112:513-20.

23. Milewicz DM, Østergaard JR, Ala-Kokko LM, Khan N, Grange DK, MendozaLondono R, et al. De novo ACTA2 mutation causes a novel syndrome of multisystemic smooth muscle dysfunction. Am J Med Genet A. 2010;152A:2437-43.

24. Munot P, Saunders DE, Milewicz DM, Regalado ES, Ostergaard JR, Braun KP, et al. A novel distinctive cerebrovascular phenotype is associated with heterozygous Arg179 ACTA2 mutations. Brain. 2012;135:2506-14.

25. Rylski B, Blanke P, Beyersdorf F, Desai ND, Milewski RK, Siepe M, et al. How does the ascending aorta geometry change when it dissects? J Am Coll Cardiol. 2014;63:1311-9. 